\title{
Geotechnical characteristics of some Iraqi gypseous soils
}

\author{
Tom Schanz ${ }^{1}$ and Hussein H. Karim ${ }^{2, *}$ \\ ${ }^{1}$ Ruhr Universität Bochum, Bochum- Germany \\ ${ }^{2}$ Building and Construction Engineering Department, University of Technology, Baghdad, Iraq
}

\begin{abstract}
In Iraq, especially in the last three decades, extensive developments have been evidenced in the regions of gypseous soils due to the need of construction of many numbers of strategic projects. Failure of different structures constructed on gypseous soil in various regions in Iraq have been noticed. For this purpose, three areas in northern Iraq were selected (Samarra, Tikrit and Baiji) to study their geotechnical characteristics due to their high gypsum contents as well as many engineering problems are faced due to dissolution of gypsum. The experimental work involves testing of many properties such as: scanning electron microscopy (SEM), XRD, chemical, physical, compressibility, collapsibility, shear strength and suction. At low stress level, the test results revealed that, higher collapse potential (CP) is recorded for Tikrit soil. While at low stress level, higher CP is obtained for Baiji soil indicating the increase in CP with decreasing gypsum content. Furthermore, the CP significantly increases with increasing stress level and soaking period at a particular stress level. According to severity classification of the collapse potential, Baiji soil is considered as moderate trouble to slight, while Tikrit soil is considered as trouble to moderate. After soaking, both soils become trouble. As well as, the results showed a reduction in Tikrit soil shear parameters $(\varphi$ and $c)$ after soaking period of 6 and $24 \mathrm{hrs}$ as 12.2 to $9.2 \%$ in the internal friction angle and 91.5 to $94.2 \%$ in cohesion, respectively with respect to dry condition. Maximum total suction is measured for low consistency soils (liquid limit $<30 \%$ ) represented by Tikrit soil.
\end{abstract}

\section{Introduction}

Soils which collapse (undergo large consolidation) when unusual amounts of water are added to them exist in many places around the world. There are many types of problematic soils, one of these is the collapsible gypseous soil. Gypseous soil is found in arid and semi-arid regions of the world where gypsum sediments and rocks are widespread such as in Iraq. There are different origins and different definitions for gypseous soil, among which is the definition proposed by Barazanji (1973) [1], who divided this soil into two main groups with respect to gypsum content namely; soil with more than 50\% known as gypsiferous soil, and soil containing less than $50 \%$ which in turn subdivided into five sub-groups.

Gypseous soils are considered as metastable or collapsible soils defined as any unsaturated soil that goes through a radical rearrangement of particles and susceptible to large abrupt volume changes and sudden collapses take place when such soils are wetted, soaked or leached with water. This can also happen when these soils are inundated under loading [2, 3]. Gypsum mineral $\left(\mathrm{CaSO}_{4} \cdot 2 \mathrm{H}_{2} \mathrm{O}\right)$ is hydrated calcium sulfate with intermediate solubility $\left(\approx 2.6 \mathrm{~g} / 1\right.$ at $\left.25^{\circ} \mathrm{C}\right)$ [3-5]. Gypsum presents in soil structure acts as a cementing material when the soil is dry.

Dudley (1970) [6] pronounced the collapse phenomenon in terms of the bonding materials existing at the contact points between soil particles. Collapse can result in a substantial rearrangement of the soil particles, resulting in a significant reduction in total volume of the soil mass. Noticeable collapse of soil demands three main conditions; an open (large void ratio), potentially unstable, partly saturated structure; a high enough value of an applied or existing stress; and a strong soil bonding or cementing agent to stabilize intergranular contacts when dry, while upon wetting will produce collapse.

In general, the settlement of gypseous soils is mainly due to the dissolution of the cementing gypsum which causes high softening of the soil and great loss in strength. So sudden increase in compressibility occurs when these soils are fully or partially saturated accompanied by structure collapse of the soil particularly in sandy gypseous soils. This can cause serious damage and even collapse of the structures founded on or in such soils $[7,8]$.

Large areas of Iraq are covered with gypseous soils, especially in the west, northwest and southwest regions and covers about $20-30 \%$ of Iraq's total area which is equivalent to about $7.3 \%$ of the total area of gypseous soils in the world [9-12].

Most hazards which are related to construction on these problematic soils occurred when such soils are subjected to water, causing softening of soils and reducing the shear strength [13-16]. Gypseous soils are highly soluble materials in their nature, and the types of problems associated with it. The failures include collapse and settlement, which can affect all construction including buildings [17-19], roads [20-22] and other

\footnotetext{
Corresponding author: husn_irq@yahoo.com
} 
engineering structures. It is worth to mention that in order to study the

behavior of such soils, it is necessary to perform scanning electron microscopy (SEM) analysis to correlate the morphological and microstructural changes with gypsum crystals dissolution or softening using different magnifications [23].

It is necessary to study the properties of such soils due to the damage caused by these soils to building on or in it. Seepage through sandy gypseous soil causes serious damage to foundation built on such type of soil. Gypsification offers a variety of serious geotechnical hazards. Such a problem causes serious danger in AlMosul dam foundation (largest dam located northern Iraq) which is built on highly gypseous soil. The seepage through the soil under foundation causes leaching and dissolution to the gypsum which brought the dam to the danger imminent of collapse, which could kill hundreds thousands of people.

The present study aims to investigate and assess the compressibility, collapse potential, shear strength and suction of gypseous soils. Three sites, located northern Baghdad-Iraq, have been chosen for their high gypsum contents.

\section{Methodology}

\subsection{Soil's location, sampling and properties}

Gypseous soil samples were taken from three sites, northern Baghdad-Iraq; namely Baiji, Tikrit and Samarra areas. These sites were chosen for two reasons; first they are characterized by their high gypsum content, while the second is the foundation problems that have occurred in area close to Baiji where Al-Mosul Dam site is located (Figure 1).

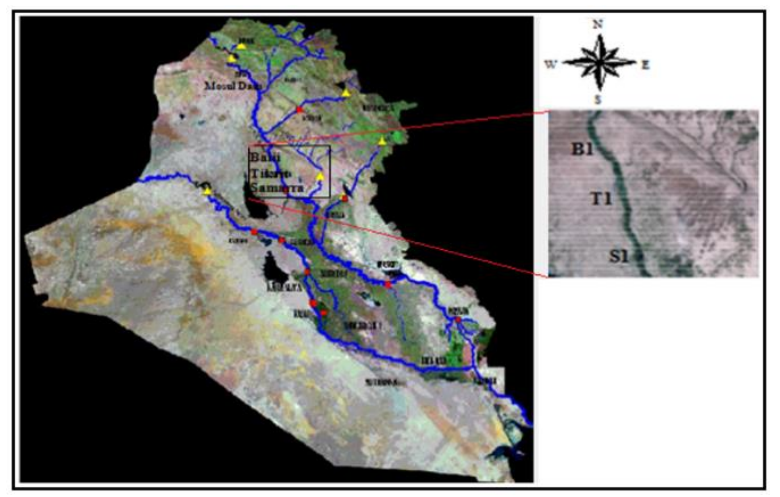

Fig. 1. Study Area.

Various tests have been carried out for such soil samples to determine their physical-chemical properties and particle size distribution. X-Ray diffraction test analyses were performed for the three soil sample kinds. The results of the mineralogical composition for the tested soil samples are shown in Table 1. Higher gypsum content is assigned to Tikrit soil sample $(73.88 \%)$, an intermediate for Samarra soil sample $(65.73 \%)$ and the lowest is assigned to Baiji soil sample (51.24\%).

\begin{tabular}{|l|c|c|c|}
\hline \multirow{2}{*}{ Mineral Type (\%) } & \multicolumn{3}{|c|}{ Site } \\
\cline { 2 - 4 } & Baiji & Tikrit & Samarra \\
\hline Gypsum & 51.24 & 73.88 & 65.73 \\
\hline Calcite & 10.81 & 9.43 & 12.21 \\
\hline Chlorite & 7.61 & 1.77 & 3.18 \\
\hline Muscovite & 10.8 & 4.23 & 4.88 \\
\hline Plagioclase (Albite) & 9.08 & 3.18 & 5.36 \\
\hline Quartz & 10.47 & 7.51 & 8.64 \\
\hline
\end{tabular}

Table 1. Mineralogical composition for the tested soil samples.

Physical tests carried out in this study including Atterberg's limits, specific gravity $\left(\mathrm{G}_{\mathrm{s}}\right)$, water content, and grain size distributions are presented in Table 2 with their standards. The Unified Soil Classification System (USCS) was used to classify the tested soils. Other standard mechanical tests performed in this study involve one-dimensional compression, collapse (single collapse test, SCT, and double oedometer test, DOT), and direct shear. A summary of soil's results for some physical properties, grain size distribution and soil classification (USCS) are summarized in Table 3.

Table 2. Tests with their standards.

\begin{tabular}{|c|c|c|}
\hline $\begin{array}{c}\text { Item } \\
\text { No. }\end{array}$ & Property & Standard \\
\hline 1 & Grain size distributions & ASTM D422 [24] \\
\hline & Specific gravity & BS 1377:6B [25] \\
\hline 2 & Atterberg's limits (L.L & BS 1377:2A [26]; \\
& and P.L) & ASTM D2216 [28] \\
\hline 3 & Water content & ASTM D3080-98 (1998) \\
\hline 4 & Direct shear tests & ASTM D 2435-04 \\
\hline 5 & One-dimensional & (2004) [30] \\
& $\begin{array}{c}\text { consolidation test } \\
\text { (Compressibility) }\end{array}$ & $\begin{array}{c}\text { ASTM D 2435, 2004 } \\
{[30] \text { ASTM D5333-03, }} \\
\text { Collapsibility test } \\
\text { (Consolidation tests) }\end{array}$ \\
\hline & & 2003 [31] \\
\hline
\end{tabular}

\subsection{Compressibility, collapsibility and shear strength of gypseous soils}

Collapsible gypseous soils show severe geotechnical and structural engineering challenges around the world. Bonds between soil particles can be formed by capillary forces (i.e. suctions) and/or by cementing of fine materials (i.e. clays or salts). When the applied vertical stresses by means of loading or wetting processes exceed yield strength of these bonding materials, various amounts of collapse potential may abruptly occur [3234]. Therefore, it is necessary to understand the process of collapse and whether the problems associated with these soils are to be avoided or mitigated. So, the geotechnical properties of gypseous soils cover, 
compressibility, collapsibility, and shear strength

\begin{tabular}{|c|c|c|c|c|c|c|c|c|c|c|c|c|c|}
\hline \multirow{3}{*}{$\begin{array}{l}\text { Soil } \\
\text { Type }\end{array}$} & \multirow{3}{*}{$\begin{array}{l}\text { Water } \\
\text { Content } \\
\text { (W.C \%) }\end{array}$} & \multirow{3}{*}{$\begin{array}{l}\text { Gypsum } \\
\text { Content } \\
\text { (G.C \%) }\end{array}$} & \multirow{3}{*}{$\begin{array}{l}\text { Specific } \\
\text { Gravity } \\
\left(G_{s}\right)\end{array}$} & \multicolumn{3}{|c|}{ Atterberg's Limits } & \multicolumn{6}{|c|}{ Grain Size Distribution \% } & \multirow{3}{*}{$\begin{array}{c}\text { Classification } \\
\text { (USCS) }\end{array}$} \\
\hline & & & & \multirow{2}{*}{$\begin{array}{l}\text { L.L } \\
(\%)\end{array}$} & \multirow{2}{*}{$\begin{array}{l}\text { P.L } \\
(\%)\end{array}$} & \multirow{2}{*}{$\begin{array}{l}\text { P.I } \\
(\%)\end{array}$} & \multirow[t]{2}{*}{$\mathrm{C}_{\mathrm{u}}$} & \multirow[t]{2}{*}{$\mathrm{C}_{\mathrm{c}}$} & \multirow{2}{*}{$\begin{array}{c}\text { Gravel } \\
(\%)\end{array}$} & \multirow{2}{*}{$\begin{array}{l}\text { Sand } \\
(\%)\end{array}$} & \multicolumn{2}{|c|}{ Fines $(\%)$} & \\
\hline & & & & & & & & & & & Silt & Clay & \\
\hline Baiji & 1.25 & 51.2 & 2.53 & 37 & 19 & 18 & 3.4 & 1.1 & 6 & 78 & 16 & - & $\mathrm{SC}$ \\
\hline Tikrit & 0 & 73.9 & 2.38 & 26 & 21 & 5 & 3.0 & 0.1 & 8 & 74 & 18 & - & SM-SC \\
\hline Samarra & 6.5 & 65.7 & 2.48 & 32 & 25 & 7 & 1.6 & 0.3 & 22 & 61 & 17 & - & SM \\
\hline
\end{tabular}

parameters $(\mathrm{c}$ and $\varphi)$ were studied.

Table 3. Summary of soil's results for some physical properties, grain size distribution and classification.

Several researchers have investigated the influence of gypsum on the copressibility characterstics. Such studies reported a decrease in the copression index with increasing gypsum content. Similar contradicting results were reported for the recompression index. Most of the researchers demonstrated an increase in the secondary compression index with increasing gypsum content. This phenomenon is attributed to the continuous dissolution process of gypsum with time as reprted by Seleam (1988) [35] and Nashat (1990) [10]. The same researchers and many others showed that the coefficient of consolidation remains unchanged with increasing gypsum content.

Al-Nouri and Al-Qaissy (1990) [36] stated that the significant reduction in shear strength is mainly due to dissolution of gypsum after wetting. Nashat (1990) [10] and Seleam (1988) [35] found that the collapse potential of gypseous soils (with gypsum content between 20-80\%) under a constant stress of $200 \mathrm{kN} / \mathrm{m}^{2}$ increases with increasing gypsum content. Petrukhin and Arkelyan (1985) [37] studied the shear strength of gypseous clayey soils with different gypsum content up to $50 \%$. This study showed that $c$ and $\varphi$ parameters are increased with increasing gypsum content upto around 15\%, then a decrease was noticed with extra increase in gypsum content.

From the above discussion, the following standard tests were performed in this study including onedimensional compression; collapse (single collapse tests); and direct shear tests supported by scanning electron microscopy technique.

\subsection{Collapse potential calculation}

The soaking collapse is caused by soaking the dry soil or partly saturated soil with water under specific pressure without flow of water. The factors that affect collapse poential $(C P)$ of gypseous soils are summarized by; soaking pressure $\left(\sigma_{w}\right)$, initial water content $\left(W_{o}\right)$, initial void ratio $\left(e_{0}\right)$, gypsum content (G.C), and duration of sustained load [38].

Gypseous soils are characterized by their collapsible behavior during wetting. The term collapse potential is used to address the hazardous case of collapsibility. Jennings and Knight (1957) [39] and Knight (1963) [40] suggested a double oedometer collapse test to predict the collapsibility of the foundation soil. Two identical samples are tested, one at natural water content and the other after submerging in water for one day. The collapse potential $(C P)$ at a specific stress is defined as [39]:

$$
C P=\frac{\Delta e}{1+e_{0}}
$$

where:

$\Delta e=$ the difference in void ratio of the two samples at a specific stress

$e_{0}=$ the natural (initial) void ratio

\section{Results and discussion}

\subsection{One dimensional compression (Oedometer) and collapse tests results}

For consolidation test, the standard oedometer device was used with the stress path of 25, 50, 100, 200, 400 and 800 $\mathrm{kPa}$ for loading stage and 400, 100 and $25 \mathrm{kPa}$ for unloading stage following the standard procedure of ASTM D 2435-04 (2004) [30]. The results of this test shown in Figure 2 are presented as e- $\log \sigma$ relation expressing void ratio versus logarithm of vertical stress relationship for the dry soil samples from Baiji and Tikrit (with initial void ratio, $e_{0}=0.28$ and 0.52 , respectively). The figure obviously shows almost a linear trend for the compressibility curves (compression and recompression curves) for both soils which can be attributed to permeability nature of gypseous sandy soil (compared to clayey soil) leading to quick settlement particularly under incremental loading.

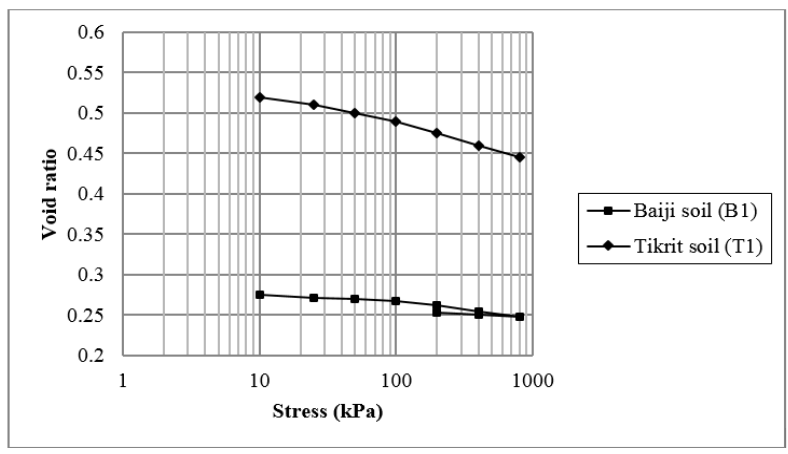

Fig. 2. Oedometer test results for Baiji and Tikrit soil samples. 
In order to investigate the range of collapse behavior of the studied gypseous soil (Baiji and Tikrit), collapse test was achieved at different conditions (drying and wetting) of soil samples following the standards for consolidation tests [30] and continued as in conventional consolidation tests [31]. The standard oedometer device was used for collapse test following the single (SOT) and double oedometer-collapse (DOT) test procedures applying the same stress sequence for loading and unloading stages for both tests.

Results of the relationship between void ratios versus vertical stress for both soils of single and double collapse-oedometer tests are presented in Figure 3 and Table 4. From the results of these tests as well as the standard oedometer test, the collapse potentials (C.P) are calculated using equation 1 .

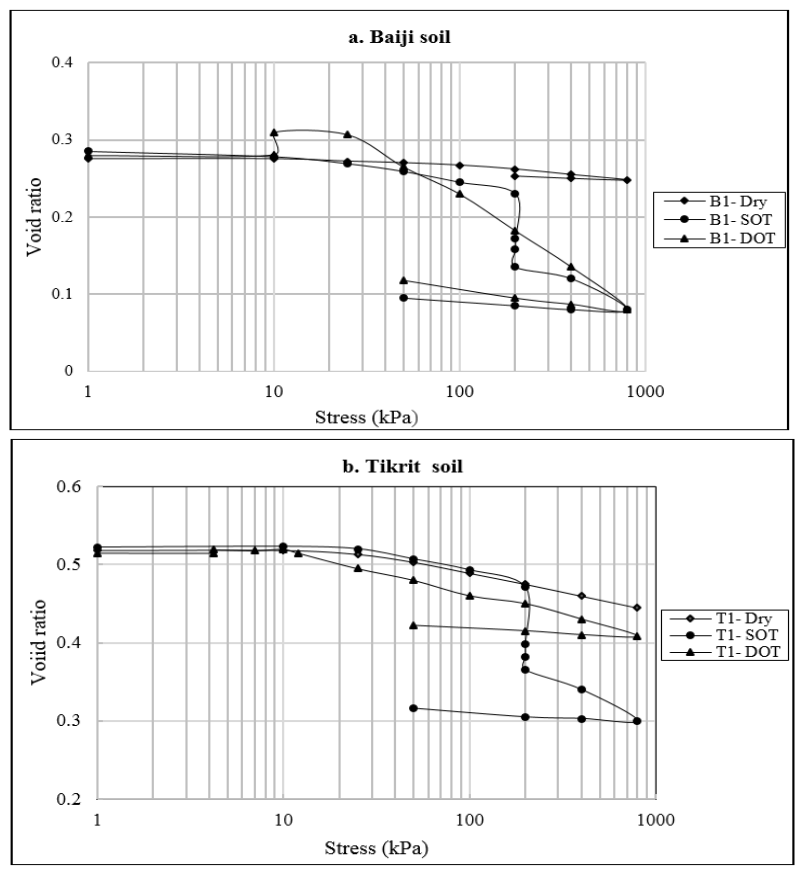

Fig. 3. Single and double oedometer tests (SOT and DOT) for: a) Baiji soil, b) Tikrit soil.

Table 4. Compression test results of for Tikrit and Baiji soils (Soaked oedometer, DOT).

\begin{tabular}{|l|c|c|c|c|c|}
\hline Site & Gs & $\begin{array}{c}\text { Gypsum } \\
\text { Content } \\
\text { (\%) }\end{array}$ & $\boldsymbol{e}_{\mathbf{0}}$ & $\boldsymbol{C}_{\boldsymbol{c}}$ & $\boldsymbol{C}_{\boldsymbol{r}}$ \\
\hline $\begin{array}{l}\text { Baiji } \\
\text { soil }\end{array}$ & 2.53 & 51.24 & 0.28 & 0.1716 & 0.033 \\
\hline $\begin{array}{l}\text { Tikrit } \\
\text { soil }\end{array}$ & 2.38 & 73.88 & 0.5163 & 0.055 & 0.011 \\
\hline
\end{tabular}

For SOT test results (Figures $3 \mathrm{a}$ and $\mathrm{b}$ ), it can be stated that the response of both soils to wetting is a "collapse" volume change. Furthermore, both natural gypseous soils show a large amount of collapse deformation and sudden volume change at independant entrance of water, where the void ratio is significantly decreased. Otherwise, at high stress level, the gap between the two values of the void ratio at unsaturated and saturated state becomes higher when the inundation took place at high stress level. This behaviour may be due to softening and breaking of gypsum bonds and the reduction of the interparticle contacts. Thus, new particles microstructure is generated with smaller volume due to densification and rearrangement. This finding was also observed by Nashat (1990) [10], Seleam (1988) [35], and Al-Obaidi (2003 and 2014) [12, 34]. The collapse behaviour for both soils is observed when the soil samples are subjected to an overconsolidation state where the soils inundation at vertical stress higher than the maximum preconsolidation pressure (where $\sigma_{\mathrm{v}}>50 \mathrm{kPa}$ for Baiji soil, and $\sigma_{\mathrm{v}}>10 \mathrm{kPa}$ for Tikrit soil) as shown in Figures $3 \mathrm{a}$ and $\mathrm{b}$.

Regarding DOT test results for Baiji soil (Figure 3a), the matching in the compressibility curves of both SOT and DOT tests is clear except that this soil undegoes a significant swelling at the beginning of the DOT test under loading levels 10,25 and $50 \mathrm{kPa}$ then the soil starts to collapse after loading level $50 \mathrm{kPa}$. This swelling volume change occurs as a response for inundation processes at stress level lower than the preconsolidation pressure (i.e. $\sigma_{\mathrm{v}}<50 \mathrm{kPa}$ ), while the collapse behaviour is observed when soil inundation at vertical stress higher than the maximum preconsolidation pressure. This behaviour may be because the soil sample was subjected to an overconsolidation state when inundation was induced at vertical stresses of 25 and $50 \mathrm{kPa}$. In other words, the volume of soil mass is being expanded when excess water is introduced filling free voids in the soil microstructure. In spite of vertical stress being applied, this did not impede the upward soil movement. Thus, a noticeable collapse settlement is observed as a result of softening and rearrangement of soil particles upon inundation at a stress level higher than the preconsolidation pressure as confirmed by findings of AlObaidi (2014) [34] and Lawton et al. (1989) [41]. While, for the DOT test for Tikrit soil (Figure 3b), no matching is observed with SOT test at $200 \mathrm{kPa}$, because the soil tested in DOT test was disturbed but the soil tested in SOT test was undisturbed and this variation might be due to remolding phenomenon.

By examining the collapse tests results of both soils for double oedometer test (DOT), one may conclude that at low stress level $(<50 \mathrm{kPa})$ the collapse potential of Tikrit soil is higher than Baiji soil due to the higher void ratio (lower density) of the former soil which is due to density effect. While at high stress level $(>50 \mathrm{kPa})$, the results are reversed that is higher collapse potential is obtained for Baiji soil than Tikrit soil which can be attributed to high compression index of soaked Baiji soil.

The comparison between collapse potential obtained by SOT and DOT collapse tests, it is well noticed that both soil samples show a collapse deformation as a result of full saturation at low vertical stress. However, relatively higher collapse potentials was obtained from SOT test than that obtained by DOT test for the same vertical stress level. The explanation for this behavior is in the SOT, all the cementing bonds of gypsum particles exist in the soil structure until sudden inundation is induced at a specified pressure. In this case, large and quick deformations occur as a result of volumetric strain 
development and cementing bonds softening by gypsum dissolution. While in DOT test, the sample is already stressed and the action of softening and dissolution of gypsum is started before reaching to a specified collapse pressure. Many studies indicate that the maximum collapse occurs when the inundation stress approaches the preconsolidation stress of the natural state compression curve, after that an increase in the degree of saturation directs the compression curve to the saturated soil curve [42, 43].

It is also shown that the collapse potential for both soils increases with increasing stress level as shown in Figure 4. Several collapse tests using DOT conducted by Iraqi studies (such as Nashat, 1990 [10]; Al-Obaidi, 2014 [34]; Seleam, 1988 [35]; Al-Badran, 2001 [38]; and Fattah et al., 2008 [44]) confirm that the collapse potential significantly increases with increasing inundation stress level particularly after the preconsolidation stress of the natural soil. In general, this behavior might be due the higher stresses (greater than the maximum preconsolidation pressure) applied on soil specimens with looser structure which will destroy and close all cavities in the specimens with an open metastable structure, then denser soil state is obtained. Also from single collapse test, collapse potentials were calculated at $200 \mathrm{kPa}$ stress level for different soaking periods during 4 days (1, 2 and 4 days). It is clear that the collapse potential increases with increasing soaked periods as shown in Figure 5 for Baiji and Tikrit gypseous soil. Depending on the severity classification of the collapse potential when inundation at $\sigma_{v}=200 \mathrm{kPa}$, Baiji soil is of moderate trouble to slight according to Jennings and Knight (1975) [45] and ASTM D5333 (2003) [31] standard respectively. While, Tikrit soil is considered as trouble to moderate at the same stress level and for the same classification respectively. After soaking, both soils become trouble at $\sigma_{v}=200 \mathrm{kPa}$.

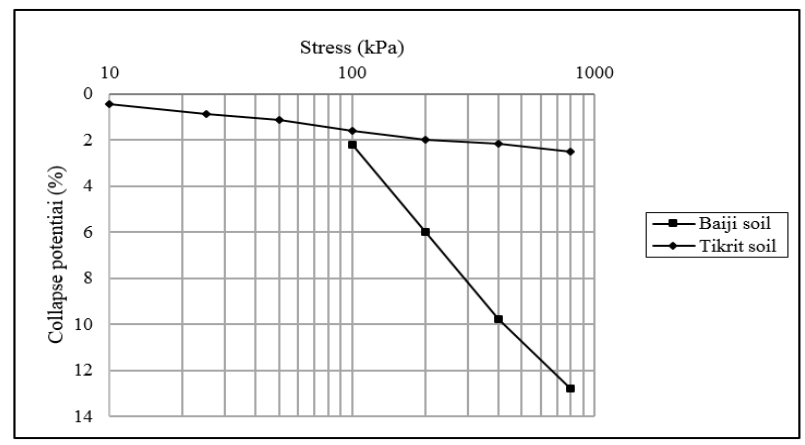

Fig.4. Collapse potential versus stress for Baiji and Tikrit soils.

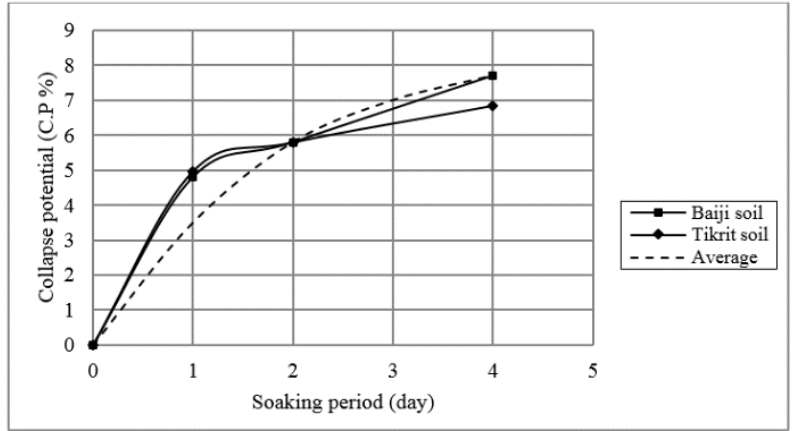

Fig. 5. Collapse potential versus time at $200 \mathrm{kPa}$ stress level for Baiji and Tikrit gypseous soils.

\subsection{Shear strength of gypseous soil}

To determine the effective shear strength parameters (cohesion, $C$, and angle of internal friction, $\varphi$ ), direct shear tests using pneumatic shear device were carried out on dry and soaked soil samples according to ASTM D 3080,1998 . The time of sample soaking in water was 6 and 24 hours. In this series, at low stress level $(<50 \mathrm{kPa})$ the collapse potential of Tikrit soil is higher than Baiji soil, three tests were conducted on 12 soil samples for Tikrit site, 4 of them were tested in dry condition, while the other 8 samples were tested in soaking condition. In order to study the effect of short-term soaking period on shear strength parameters of gypseous soil, the first four samples were soaked for $24 \mathrm{hrs}$, while the rest samples were soaked for $6 \mathrm{hrs}$. The normal stresses were 50, 100, 200 and $400 \mathrm{kPa}$.

Figure 6 and Table 5 present the results of direct shear test of Tikrit soil for the conditions of dry, after $6 \mathrm{hrs}$ soaking and $24 \mathrm{hrs}$ soaking. It can be seen that the percentage of reduction in the angle of internal friction $(\varphi)$ and cohesion $(c)$ due to soaking were $12.24 \% ; 91.5$ $\%$ and $9.2 \%$; $94.24 \%$ for soaking 6 and $24 \mathrm{hrs}$ respectively. It is well noticed the loss in strength by soaking, basically in cohesion, which is mainly due to softening. 


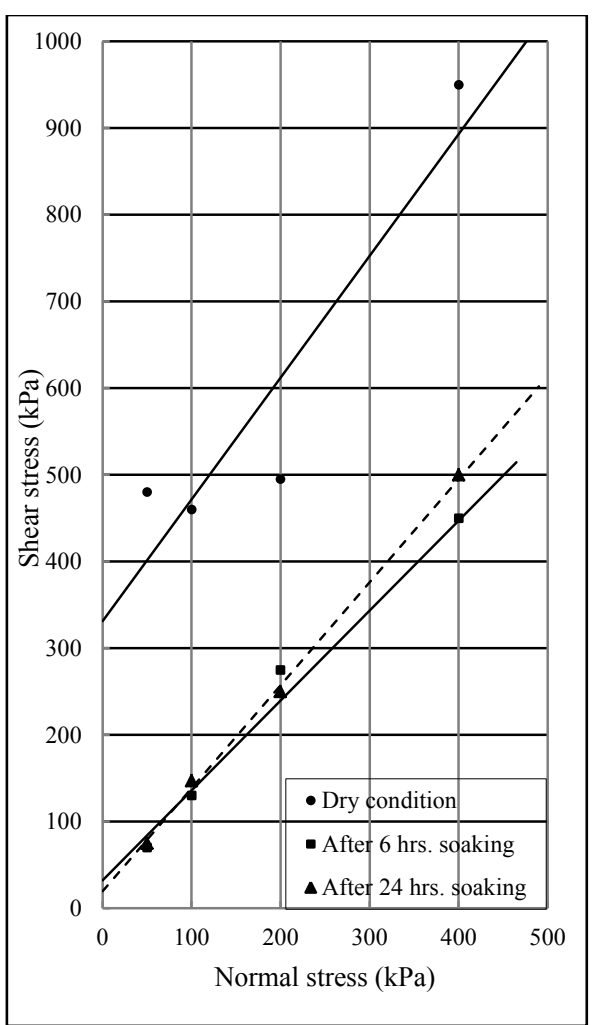

Fig. 6. Direct shear test results for Tikrit soil sample for the conditions of dry, after 6 and 24 hrs soaking.

Table 5. Shear strength parameters for Tikrit gypseous soil.

\begin{tabular}{|c|c|c|c|c|c|}
\hline \multicolumn{4}{|c|}{ Shear Strength Parameters } \\
\hline \multicolumn{3}{|c|}{$c$ (kPa) } & \multicolumn{3}{c|}{$\varphi\left(^{\circ}\right)$} \\
\hline Dry & $\begin{array}{c}\text { After } \\
\text { soaking } \\
(6 \text { hrs. })\end{array}$ & $\begin{array}{c}\text { After } \\
\text { soaking } \\
(24 \text { hrs. })\end{array}$ & Dry & $\begin{array}{c}\text { After } \\
\text { soaking } \\
(6 \text { hrs.) }\end{array}$ & $\begin{array}{c}\text { After } \\
\text { soaking } \\
(24 \text { hrs. })\end{array}$ \\
\hline 330 & 28 & 19 & 49 & 43 & 44.5 \\
\hline
\end{tabular}

To illustrate the behavior of such soils under the effect of both soaking and/or loading on microstructural changes, scanning electron microscopy (SEM) was carried out under different conditions (dry, after 6 and 24 hrs soaking). SEMs of the natural soil samples (Figures $7 \mathrm{a}, 8 \mathrm{a}$, and 9a) show the presence of gypsum in different shapes (flatty and platy sheets, scattered crystals and as crust encasing soil particles). These gypsum crystals act as a bonding material between soil particles. After soaking (Figures $7 b, 8 b$, and $9 b$ ), SEM results point out appreciable microstructural changes which are well identified as voids and solid regions in the micrographs. Besides, these figures show the soil softenning by partial dissolution of gypsum particles due to soaking and forming voids between soil particles which may lead to collapsibility. While, when the soil sample is subjected to flooding and loading (after single collapse test) (Figure $7 \mathrm{c}$ ), the soil grains are weakened by breaking gypsum bond particles due to partial dissolution after soaking and resulting in large voids. With additional load, soil grains may slide one over another resulting in collapse as confirmed by Jefferson and Rogers (2012) [33] and Karim et al. (2015) [23]. Consequently, the tested gypseous soils exhibit a loss of strength basically in cohesion over internal friction angle which is well observed for soaked specimens due to softening bonds destruction and reduction in the inter-particle contacts in the soil after soaking.

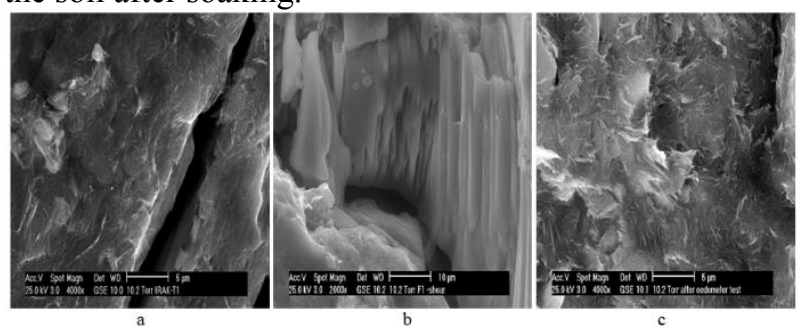

Fig. 7. a) SEM for Tikrit natural soil. b) SEM after short-term soaking. c) SEM after subjecting to single collapse test.

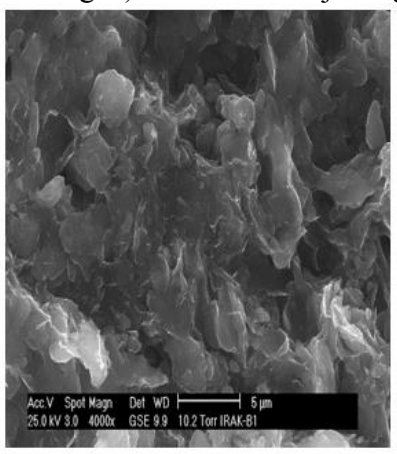

a

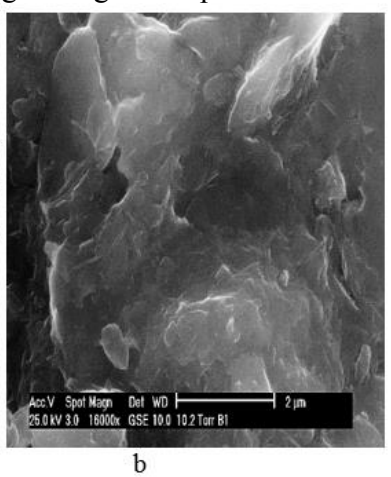

b
Fig. 8. a) SEM for Baiji natural soil. b) SEM after short-term soaking.

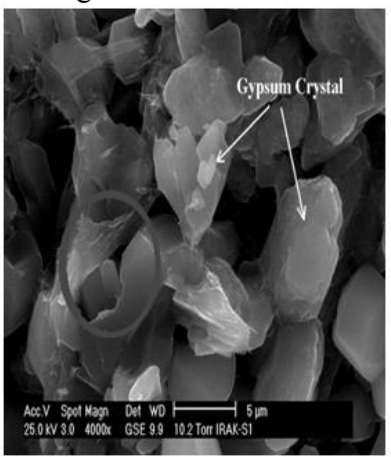

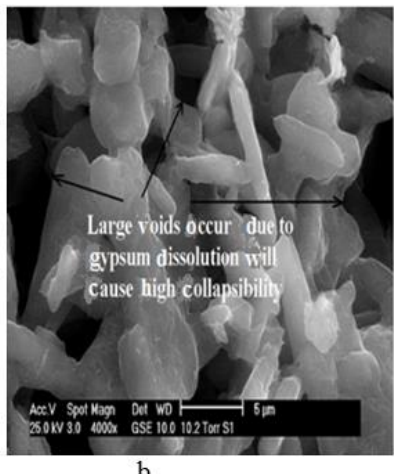

Fig. 9. a) SEM for Samarra natural soil. b) SEM after shortterm soaking.

\subsection{Suction measurements and related parameters}

This test was carried out to investigate the behavior of soils when subjected to suction. The relationships of suction with water content, volumetric water content, degree of saturation and void ratio for Baiji, Tikrit, and Samarra gypseous soils are respectively shown in Figure $10 \mathrm{a}$ to $\mathrm{d}$. It is worth mentioning that depsite the suction measurements were incomplete, they may diplay part of these relationships. The test results for the three selected soils clearly show large reductions in their water content, volumetric water content, degree of saturation and void ratio as a result of successive increases in suction values. 


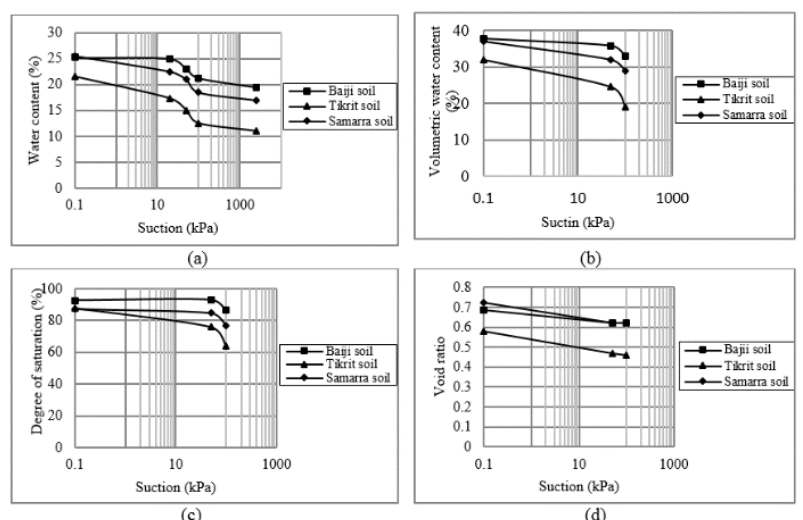

Fig. 10. Relationships of suction with water content, volumetric water content, degree of saturation and void ratio for Baiji, Tikrit, and Samarra gypseous soils.

The chilled-mirror hygrometer technique was used to determine and monitor the total suction of soil specimens. It is an indirect method to measure total suction. It uses a dew-point measurement method and the device is a water activity meter by which the relative humidity of the specimens was measured and the total suction was calculated using the thermodynamic relationship between soil suction, or the free energy of the soil-water and the partial pressure of the pore water vapor (Kelvin's equation) as follows:

$$
\psi=\frac{R T}{v_{w_{o}} w_{v}} \ln \left(\frac{\bar{u}_{v}}{\bar{u}_{v_{o}}}\right)
$$

where: $\psi=$ soil suction or total suction $(\mathrm{kPa}), \mathrm{R}=$ universal (molar) gas constant (i.e., $8.31432 \mathrm{~J} /(\mathrm{mol} \mathrm{K})), T_{K}=$ absolute temperature (i.e., $\quad(273.15+\mathrm{T} \quad(\mathrm{K}))$, $\mathrm{T}=$ temperature, ${ }^{\circ} \mathrm{K}, v_{w_{o}}=$ specific volume of water or the inverse of the density of water (i.e., $1 / \rho_{w}, \mathrm{~m}^{3} / \mathrm{kg}$ ), $\rho_{w}=$ density of water (i.e., $998 \mathrm{~kg} / \mathrm{m}^{3}$ at temperature $=200^{\circ} \mathrm{C}$ ), $w_{v}=$ molecular mass of water vapor (i.e., $18.016 \mathrm{~kg} / \mathrm{kmol}), \bar{u}_{v}=$ partial pressure of pore water $(\mathrm{kPa})$, and $\bar{u}_{v_{o}}=$ saturation pressure of water vapor over a flat surface of pure water at the same temperature $(\mathrm{kPa})$. The term $\left(\frac{\bar{u}_{v}}{\bar{u}_{v_{o}}}\right)$ is called the relative humidity $(\mathrm{RH})$ and is entered as a function (i.e., water activity) in the above equation.

The total suction of soil samples were measured using the chilled-mirror hygrometer according to ASTM D6836-2008 [46] standard. The total suction-water content relationship calculated from chilled-mirror hygrometer for the three soils is illustrated in Figure 11. The figure indicates that the suction increases with decrease of the water content. The suction curves especially for Baiji and Samarra soils are almost similar to one another, particularly in the higher water content range, while the curve for Tikrit soil is somewhat different. It is shown that the total initial suction at hygroscopic water content for Baiji, Samarra, and Tikrit gypseous soils are 300 000, 180000 and $1600000 \mathrm{kPa}$, respectively. It is worth mentioning that low liquid limit is obtained for the latter soil. Thus, the maximum suction measured for Tikrit natural soil due to its low consistency
(L.L $<30 \%)$ as well as its high amount of gypsum $(73.88$ $\%$ ) could be the reason for this difference.

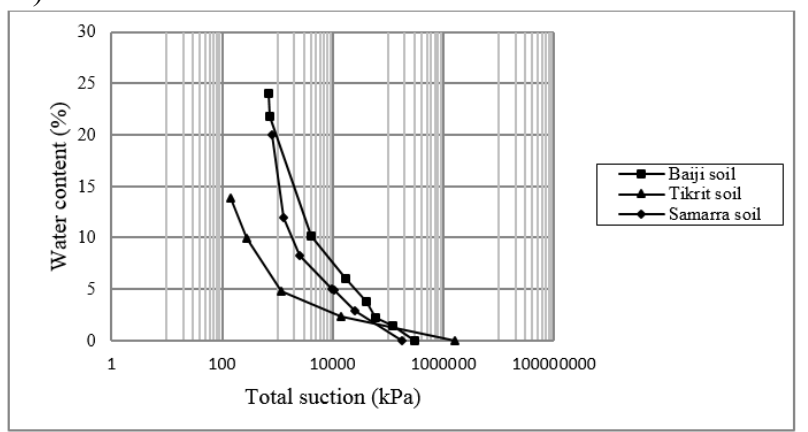

Fig. 11. Relation of total suction with water content.

\section{Conclusions}

In this work, a comprehensive laboratory investigation was undertaken to study the collapsibility and shear strength for three Iraqi site locations with different gypsum contents. In the light of experimental test results, the following conclusions can be drawn:

1. The tested gypseous soils exhibit very high shear strength when dry, and by comparing failure envelopes of dry specimens with those of soaked specimens, a loss of strength basically in cohesion is observed in the soaked ones.

2. For Baiji gypseous soil sample, the DOT test showed soil swelling at the beginning of the test under the stress levels 10,25 and $50 \mathrm{kPa}$ which then started to collapse after loading level $50 \mathrm{kPa}$.

3. The results of collapse potential-stress relationship show that the CP increases with increasing stress level for both Baiji and Tikrit soil samples. Moreover, Baiji gypseous soil (with lowest gypsum content) exhibits higher CP values at high stress level compared to Tikrit gypseous soil (with highest gypsum content) indicating the increase in $\mathrm{CP}$ with decreasing gypsum content.

4. At low stress level $(<50 \mathrm{kPa})$, the collapse potential of Tikrit soil is higher than Baiji soil due to the lower density of the former soil. While at high stress level $(>50 \mathrm{kPa})$, the results are reversed for the soaked Baiji soil which can be attributed to its high compression index.

5. From single oedometer tests (SOT), collapse potentials were calculated at $200 \mathrm{kPa}$ stress level for different soaking periods within 4 days. The results showed that the collapse potential increases with increasing soaking periods for both types of gypseous soils tested. According to severity classification of the collapse potential, Baiji soil is considered as moderate trouble to slight. While Tikrit soil is considered as trouble to moderate. After soaking, both soils become trouble.

6. For Tikrit site, the percent of reduction in the angle of internal friction were $12.2 \%$ and $9.2 \%$, while in cohesion were $91.5 \%$ and $94.2 \%$ due to soaking for 6 and $24 \mathrm{hrs}$ respectively. 
7. The maximum suction measured was for Tikrit natural soil due to its low consistency (L.L $<30 \%$ ) as well as its high amount of gypsum.

This work was supported by Iraqi Ministry of High Education and Scientific Research as part of Ph.D Thesis entitled Geotechnical Engineering Study for Salah Al-Din Governorate Using Geophysical and Remote Sensing Techniques, University of Technology, Iraq. Sincere thanks is expressed to the staff of the Soil Mechanics Laboratory at Bauhaus-Universität Weimar in Germany for their assistance in carrying out the laboratory tests. Deep thanks is also expressed to F.A. Finger-Institute and to the Chemical Laboratories at Bauhaus-Universität Weimar for ESEM, X-Ray and chemical tests.

\section{References}

1. A.F. Barazanji, Soil of Iraq, Ph.D. Thesis, State University of Ghent, Belgium, (1973)

2. S.P. Clemence, A.O. Finbarr, J Geotech Eng Div, Proc. ASCE 107, 305-317 (1981)

3. Z.M. Mansour, Z. Chik, M.R. Taha, J Appl Sci 8, 4434-4439 (2008)

4. E. Bock, Can J Chem 39, 1746-1751 (1961)

5. J. Herrero, J. Porta, Geoderma 96, 47-61 (2000)

6. J.H. Dudley, ASCE J Soil Mech Found Div 96, 925947 (1970)

7. R.N. Arutyunyan, Soil Mech Found Eng 15, 183-185, (1978)

8. S.S. Razouki, R.R. Al-Omari, I.H. Nashat, H.F. Razouki, S. Khalid, Proceedings of the symposium on gypsiferous soils and their effect on structures, NCCL, 7-33 (Baghdad, 1994)

9. FAO, Management of gypsiferous soil, Bulletin No. 62, (Rome, Italy, 1990)

10. I.H. Nashat, Ph.D Thesis, University of Baghdad, Baghdad, Iraq, (1990)

11. A. Al-Mufty, Ph.D Thesis, University of Baghdad, Baghdad, Iraq, (1997)

12. Q.A. Al-Obaidi, M.Sc. Thesis, Al- Mustansiriyah University, Baghdad, Iraq, (2003)

13. S.S. Razouki, O.A. El-Janabi, Q J Eng Geo Hydroge 31, 87-89 (1999)

14. B.S. Albusoda, M.Sc. Thesis, University of Baghdad, Baghdad, Iraq, (1999)

15. A. Ismail, W.J. Hilo, J App Sci 8, 4610-4616 (2008)

16. M.A. Al-Dabbas, T. Schanz, M. J. Yassen, Arab J Geosci 22, 111-119 (2010)

17. R.N. Arutyunyan, A.V. Manukyan, Soil Mech Found Eng 19, 151-154 (1982)

18. A.H. Cooper, Eng Geol, Special Publication 15, 265 275 (1998)

19. A.H. Cooper, Q J Eng Geo Hydroge 41, 409-424 (2008)

20. A.A. Ahmad, M.Sc. Thesis, University of Mosul, Mosul, Iraq, (1985)

21. S.A. Aiban, H.I. Al-Abdul Wahhab, O.S.B. AlAmoudi, H. R. Ahmed, Constr Build Mater 12, 329340 (1998)

22. M. Hua, B. Wang, L. Chen, Y. Wang, V.M. Quynh, B. He, X. Li, Fuel 89, 1812-1817 (2010)
23. H.H. Karim, T. Schanz, A.N. Ibrahim, Proceedings of the $2^{\text {nd }}$ international conference of buildings, construction and environmental engineering, American University of Beirut (BCEE2), 17-18 Oct., 2015, Geotechnical Engineering part, 95-100 (2015)

24. ASTM D422, Particle-size analysis of soils, (ASTM International, West Conshohocken, PA, United States, 2007)

25. BS 1377:6B, Method of test for soils for civil engineering purposes, Chemical and electro-chemical tests, (British Standard Institution, London, UK, 1990)

26. BS 1377:2A, Method of test for soils for civil engineering purposes, (British Standard Institution, London, UK, 1990)

27. BS 1377:3, Method of test for soils for civil engineering purposes, Chemical and electro-chemical tests, (British Standard Institution, London, UK, 1990)

28. ASTM D2216, Laboratory determination of water (moisture) content of soil and rock by mass, (ASTM International, West Conshohocken, PA, United States, 2010)

29. ASTM D3080, Standard test method for direct shear test of soils under consolidated drained conditions, (ASTM International, West Conshohocken, PA, United States, 1998)

30. ASTM D2435-04, Standard test methods for onedimensional consolidation properties of soils using incremental loading, (ASTM International, West Conshohocken, PA, United States, 2004)

31. ASTM D5333-03, Standard test method for measurement of collapse potential of soils, (ASTM International, West Conshohocken, PA, United States, 2003)

32. S. Houston, W. Houston, C. Zapata, C. Lawrence, Geotech Geol Eng 19, 333-355 (2001)

33. I. Jefferson, C. Rogers, ICE manual of geotechnical engineering, Vol. 1 of ICE manuals (ICE Publishing, London, UK, 2012)

34. Q.A.J. Al-Obaidi, Ph.D Dissertation, Faculty of Civil and Environmental Engineering, Ruhr- Universität Bochum, Bochum, (2014)

35. S.N.M. Seleam, M.Sc. Thesis, University of Technology, Baghdad, Iraq (1988)

36. J.A. Al-Nouri, F.F. Al-Qaissy, Symposium on recent advances in geotechnical engineering, 8-14, Singapore, (1990)

37. V.P Petrukhin, E.A. Arkelyan, Soil Mech Found Eng 21, 23-25 (1985)

38. Y.M. Al-Badran, M.Sc. Thesis, University of Baghdad, Baghdad, Iraq, (2001)

39. J.E. Jennings, K. Knight, Proceeding $4^{\text {th }}$ international conference on soil mechanics and foundation engineering, 1, 316-319 (1957)

40. K. Knight, Proc. of $3^{\text {rd }}$ regional conference of Africa on soil mechanics and foundation engineering, 1, 127-130 (1963)

41. E. Lawton, R. Fragaszy, J. Hardcastle, J Geotech Eng 115, 1252-1267 (ASCE, 1989)

42. Z. Lin, S. Wang, Eng Geo 25, 271-282, (1988) 
43. A. Al-Mufty, International conference on geotechnical engineering-Beirut, (2004)

44. M. Fattah, Y. Al-Shakarchi, H. Al-Numani, Eng Tech J 26, 1461-1485 (2008)

45. J. Jennings, K. Knight, Proc. 6th African conf. soil mechanics and foundation engineering, Durban, 99105 (1975)

46. ASTM D6836, Standard test methods for determination of the soil water characteristic curve for desorption using a hanging column, pressure extractor, chilled mirror hygrometer, and/or centrifuge, (ASTM International, West Conshohocken, PA, United States, 2008) 